\title{
$\operatorname{con} F-9206162-12$
}

DOE/MC/93008-96/C0539

Separation of Hydrogen Using Thin Film Palladium-Ceramic Composite Membrane

Authors:

Shamsuddin Ilias

Franklin G. King

Contractor:

North Carolina A\&T State University

Office of Research Administration

Suite 305, Dowdy Administration Building

Greensboro, NC 27411
$\mathrm{Nan} \mathrm{Su}$

Uduak I. Udo-Aka

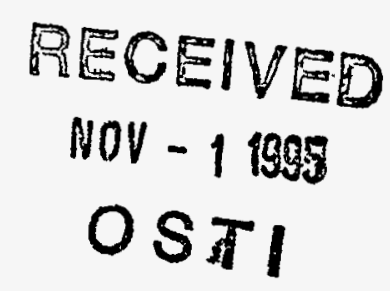

Contract Number:

DE-FG22-93MT93008

Conference Title:

Advanced Coal-Fired Power Systems '95 Review Meeting

Conference Location:

Morgantown, West Virginia

Conference Dates:

June 27-29, 1995

\section{Conference Sponsor:}

U.S. Department of Energy, Morgantown Energy Technology Center (METC) 


\section{DISCLAIMER}

This report was prepared as an account of work sponsored by an agency of the United States Government. Neither the United States Government nor any agency thereof, nor any of their employees, makes any warranty, express or implied, or assumes any legal liability or responsibility for the accuracy, completeness, or usefulness of any information, apparatus, product, or process disclosed, or represents that its use would not infringe privately owned rights. Reference herein to any specific commercial product, process, or service by trade name, trademark, manufacturer, or otherwise does not necessarily constitute or imply its endorsement, recommendation, or favoring by the United States Government or any agency thereof. The views and opinions of authors expressed herein do not necessarily state or reflect those of the United States Government or any agency thereof.

This report has been reproduced directly from the best available copy.

Available to DOE and DOE contractors from the Office of Scientific and Technical Information, 175 Oak Ridge Turnpike, Oak Ridge, TN 37831; prices available at (615) 576-8401.

Available to the public from the National Technical Information Service, U.S. Department of Commerce, 5285 Port Royal Road, Springfield, VA 22161; phone orders accepted at (703) 487-4650. 


\section{B.2 Separation of Hydrogen Using Thin Film Palladium-Ceramic Composite Membrane}

CONTRACT INFORMATION

Contract Number

Contractor

Contractor Project Manager

Principal Investigators

METC Project Manager

Period of Performance
DE-FG22-93MT93008

North Carolina A\&T State University

Office of Research Administration

Suite 305, Dowdy Administration Building

Greensboro, NC 27411

(910) 334-7995

Shamsuddin Ilias

Shamsuddin Ilias

Franklin G. King

Nan Su

Uduak I. Udo-Aka

Venkat $\mathrm{K}$. Venkataraman

September 01, 1993 to August 31, 1996

\section{OBJECTIVES}

The primary objective of this study was to prepare and characterize a hydrogen permselective palladium-ceramic composite membrane for high temperature gas separations and catalytic membrane reactors. Electroless plating method was used as a potential route to deposit a thin palladium film on microporous ceramic substrate. The objectives of the work presented here were to characterize the new Pd-ceramic composite membrane by SEM and EDX analysis and to carry out fundamental permeability measurements of the membrane at elevated temperatures and pressures.

\section{BACKGROUND INFORMATION}

From environmental and energy considerations, it is generally recognized that membrane separation processes could become wide spread in industrial applications. In recent years, considerable attention has focused on combining the unit operations of separation and reaction to provide purer products by shifting of thermodynamic equilibria [1-3]. The use of membranes to remove products from the reaction zone has obvious industrial interest since it provides lower reaction temperatures, smaller reactors, and reduced downstream separation costs. 
The potential application of membranes in high temperature gas separation and reactor technology have been recognized by many investigators. For example, in the coal gasification process, the exit gases are normally hydrogen, carbon monoxide, carbon dioxide, hydrogen sulfide, and water vapor. The objective is to obtain hydrogen from this gas mixture. Currently, it is uneconomical to recover hydrogen because no suitable recovery method exists that can be implemented at high temperatures and pressures. This process' economics is improved if hydrogen can be recovered at a lower cost.

Many heterogeneous catalytic reactions can not reach high conversions because of the limits imposed by the reaction equilibrium. For example, the dehydrogenation reaction of cyclohexane, catalyzed with platinum/alumina at $215^{\circ} \mathrm{C}$ in a conventional reactor, is limited to $33 \%$ conversion [3]. If, however, the product hydrogen is continuously removed from the reaction mixture through an inorganic membrane, the equilibrium is displaced towards the product side and the conversion has been shown to increase to nearly $80 \%$. Since, this reaction is favored by an increase in temperature, it can also be said that the temperature needed for desired conversion can be lowered. This principle can be applied to several other industrially significant reactions. The efficiency of the process depends on the effectiveness of hydrogen removal. Hence, the conversion of reactants can be enhanced dramatically if a method can be developed for recovering hydrogen at higher temperatures.

Recently, there has been increased interest in developing inorganic and composite membranes for in-situ separation of product hydrogen to achieve equilibrium shift in catalytic reactor [4-7]. However, the productivity of these membrane reactors are severely limited by the poor permeability of currently available membranes. Commercially available non-porous membranes are either thick film or thick walled tubes. Since, permeability is inversely proportional to film thickness, a thick film membrane acts as a poor permseparator. Thus, a major challenge lies in developing a permselective thin film, without compromising the integrity of the film. The success of membranes in these applications will largely depend on the availability of membranes with acceptable permselectivity and thermal stability [5]. The availability of such a membrane for high temperature application could open new areas of research in membrane reactor technology and gas separation.

The development of a process for producing ultra-thin, defect-free composite membranes is important. If such a process is to be developed in a generally applicable form for use with most advanced materials, a high-productivity, high-selectivity coating must be applied on an inexpensive support. To develop a new class of permselective inorganic membranes, we have used electroless plating to deposit a palladium thin-film on a microporous ceramic substrate [8]. Electroless plating is a controlled autocatalytic deposition of continuous film on the surface of a substrate by the interactions of a metal salt and a chemical reducing agent. This method can be used to make thin films of metals, alloys and composites on both conducting and nonconducting surfaces.

\section{PROJECT DESCRIPTION}

Electroless Plating of Ceramic Substrate

Microporous ceramic alumina 
membranes ( $\alpha$-alumina, $\phi 39 \mathrm{~mm} \times 2 \mathrm{~mm}$ thickness, nominal pore size $150 \mathrm{~nm}$ and open porosity $\approx 42 \%$ ) were coated with a thin palladium film by electroless plating. Electroless plating is explained by a combination of the cathodic deposition of metal and the anodic oxidation of reductant at the immersion potential.

Electroless plating is a three step process involving pretreatment of the substrate, sensitization and activation of the substrate surface, and electroless plating. The procedure developed in this work for electroless deposition of palladium thin film on microporous ceramic substrate has been reported elsewhere [8].

\section{Membrane Characterization}

The characterization of the membrane included the physical property study as well as the diffusion measurements. The membranes were studied by taking SEM micrograph, EDX analysis and measuring the thickness of the coated film. A steady state counter diffusion method, using gas chromatographic analysis, was used to evaluate the permeability and selectivity of the composite palladium membrane for hydrogen separation. A schematic of the permeability measurement system is shown in Figure 1.

\section{RESULTS}

In this work, thin-film Pd-ceramic composite membrane was developed by electroless deposition of palladium on planar ceramic substrate. The new membrane was characterized and evaluated for hydrogen separation at high temperatures.

The composition of the palladiumceramic composite membrane surface was evaluated by EDX analysis. The EDX analysis of the membrane specimen is shown in Figure 2. The analysis showed that the palladium film deposited on the ceramic substrate is highly pure. The film thickness was estimated by weight gain method.

In Figure 3, the SEM micrographs of a composite membrane specimen are shown for the ceramic substrate, sensitized and activated substrate surface and the electroless deposited palladium film on ceramic substrate. From SEM micrographs, no significant surface modifications were observed after the substrate was activated and sensitized. The pore size remained more or less the same. However, after the coating, the surface structure changed dramatically. Pores were fully covered by solid palladium film and no pin holes were detected.

Steady state method was used to measure the effective diffusivity of hydrogen through the ceramic substrate. Experiments were conducted at an operating pressure of 5 psig with zero transmembrane pressure and temperatures ranging from $28^{\circ} \mathrm{C}$ to $225^{\circ} \mathrm{C}$. Figure 4 suggests that the relationship between diffusivity and temperature can be correlated as following:

$$
D_{e}=D_{e o} \exp \left(\frac{-E_{D}}{R T}\right)
$$

where $R$ is the universal gas constant $\left(\mathrm{J} \cdot \mathrm{mole}^{-1} \cdot \mathrm{K}^{-1}\right), \quad \mathrm{T}$ is the absolute temperature $(\mathrm{K}), \mathrm{D}_{\mathrm{co}}$ is the pre-exponential factor in the Arrhenius relationship for hydrogen diffusivity $\left(\mathrm{cm}^{2} \cdot \mathrm{sec}^{-1}\right)$ and $E_{D}$ is the apparent diffusivity activation energy of the substrate $\left(\mathrm{J} \cdot \mathrm{mole}^{-1}\right)$. The effective diffusion coefficient, $D_{e}$, at other temperatures can be calculated using the 
above equation once the $\mathrm{D}_{\mathrm{co}}$ and $-\mathrm{E}_{\mathrm{D}} / \mathrm{R}$ are known from the linear plot of Figure 4.

Effect of temperatures at various transmembrane pressure drop on hydrogen transport through the substrate was a also investigated in this work. For a porous membrane, one would expect the flux to obey the following relationship with $n=1$ :

$$
N_{H_{2}}=\frac{D_{e}}{R T}\left(\frac{\left(P_{H_{2}}\right)_{H_{2}}^{n}-\left(P_{H_{2}}\right)_{A r}^{n}}{d}\right)
$$

For the experimental hydrogen flux data, the value of $\mathrm{n}$ was estimated by using the Marquardt-Levenberg non-linear least square analysis and was found to be 1.0003 . A value of $n$ equal to 1 implies that the transport of hydrogen through the substrate is not solubility dependent. Given the experimental uncertainty, it will be fair to say that in our case the transport of hydrogen through the substrate is solubility independent and $\mathrm{n}$ is taken as 1. With increasing pressure drop at a given temperature, the hydrogen flux through the substrate is seen to increase. However, with increasing temperature, the flux was observed to decrease. The results are shown in Figure 5.

Two thin-film palladium-ceramic membrane specimens were fabricated by electroless deposition method as discussed in the previous section. By weight-gain method, the palladium film thicknesses were estimated to be $8.5 \mu \mathrm{m}$ and $12 \mu \mathrm{m}$. The permeability experiments were conducted at temperatures of $373 \mathrm{~K}, 473 \mathrm{~K}$ and $573 \mathrm{~K}$. The pressure on the high pressure side ranged from 10 psig to 20 psig and the low pressure side was maintained at $5 \mathrm{psig}$ in all permeability measurement experiments.
The hydrogen flux through metallic dense film may be described by [9]:

$$
N_{H_{2}}=\frac{P_{H}}{h}\left[\left(P_{H_{2}}\right)_{H_{2}}^{n}-\left(P_{H_{2}}\right)_{A r}^{n}\right]
$$

where $P_{H}$ is the permeability coefficient and $h$ is film thickness. When diffusion through the bulk metal is the rate limiting step, and hydrogen atoms form ideal solution in the metal, then according to Sievert's law hydrogen solubility dependence $n$ equals to 0.5 . However, a value of $n$ greater than 0.5 may result when surface processes influence the permeation rate or when the Sievert's law is not followed.

Based on Eqn. (3), the hydrogen flux data were analyzed to estimate the value of $\mathrm{n}$ by using the Marquardt-Levenberg nonlinear least square method. For the $8.5 \mu \mathrm{m}$ and $12 \mu \mathrm{m}$ films, the average values of $n$ were estimated as 0.778 and 0.5006 , respectively. From this analysis, it appears that a palladium film of $12 \mu \mathrm{m}$ thickness approaches the limiting definition of dense Pd-film according to Sievert's law.

With average values of $n$ equal to 0.778 and 0.5006 for $8.5 \mu \mathrm{m}$ and $12 \mu \mathrm{m} \mathrm{Pd-film}$ composite membranes, the hydrogen fluxes are plotted against driving force $\left(\left(\mathrm{P}_{\mathrm{H}_{2}}\right)_{\mathrm{H} 2}{ }^{n}\right.$ $\left.\left(\mathrm{P}_{\mathrm{H}_{2}}\right)_{\mathrm{Ar}}{ }^{\mathrm{n}}\right)$ in Figures 6 and 7, respectively. At a given temperature, the slope of the line provides value of $P_{H} / h$. Since the membrane film thickness is known, one may calculate the membrane permeability from the known slopes of the lines at various temperatures as shown in Figures 6 and 7. From these Figures, it can be seen that the hydrogen fluxes increase with increasing temperature at a given driving force $\left(\left(\mathrm{P}_{\mathrm{H} 2}\right)_{\mathrm{H} 2}{ }^{\mathrm{n}}-\left(\mathrm{P}_{\mathrm{H} 2}\right)_{\mathrm{Ar}}{ }^{\mathrm{n}}\right)$. This flux behavior is exactly opposite to what we observed in the case of substrate 
(Figure 5). This is not an unexpected results. It suggests that a substrate coated with a selective separating layer, the flux of the selective gas component can be increased by increasing the temperature. Therefore, the new membrane will be suitable for separation of hydrogen at high temperatures.

\section{FUTURE WORK}

During the next fifteen months of the project, we plan to work on the following tasks:

- Evaluate the fabricated membrane for permeability and selectivity of hydrogen in presence of other gases such as argon, methane, nitrogen and carbon dioxide.

- Evaluate the economics of recovery of hydrogen from coal gasification process using the new thin film palladiumceramic composite membrane.

- Extend this membrane development work to palladium-alloy ceramic composite membrane for hydrogen separation.

\section{ACKNOWLEDGEMENT}

The authors wish to thank Drs. Carl Udovich, Gary P. Hagen and Vasu Kulkarni, Amoco Chemical Company R\&D Center, Naperville, for many of their invaluable suggestions and discussions.

\section{REFERENCES}

1. Itoh, N., Xu, W-C., and Haraya, K., "Basic Experimental Study on Palladium Membrane Reactors," J. Mem. Sci.,
66, 149 (1992).

2. Edmund, D.J., and Pledger, W.A., "Thermolysis of Hydrogen Sulfide in a Metal-Membrane Reactor," J. Mem. Sci., 77, 255 (1993).

3. Itoh N., and Govind R., "Development of a Novel Oxidative Palladium Membrane Reactor," AIChE Symposium Series 268, 85, 10 (1989).

4. Sun, Y.M., and Khang, S.J., "Catalytic Membrane for Simultaneous Chemical Reaction and Separation Applied to a Dehydrogenation Reaction," Ind. Chem. Eng. Res., 27(7), 1136 (1988).

5. Itoh, N., "Development of a One-side Uniform Model for Palladium Membrane Reactors, " J. Chem. Eng. Japan, 25(3), 336 (1992).

6. Ohata, Y., Gondaira M., Kobayashi K., Fujimoto, Y., and Kuroda, K., "Study on the Performance of a Stream Reformer of Town Gas Equipped with Palladium Membranes," 1994 AIChE Annual Meeting, San Francisco, Paper No. 76i (1994).

7. Ilias, S., and Govind, R., "Development of High Temperature Membrane for Membrane Reactor: an Overview, " AIChE Symposium Series 268, 85, 18 (1989).

8. Ilias, S., King, F.G., and Su, N., "Preparation and Characterization of Composite Membrane for High Temperature Gas Separation," Proc. Coal-Fired Power Systems 94 Advances in IGCC and PFBC Review Meeting, Morgantown, WV, vol. II, pp. 721-26 (1994).

9. Uemiya, S., Sato, N., Ando, H., and Kikuchi, E., "The Water Gas Shift Reaction Assisted by a Palladium Membrane Reactor, "Ind. Eng. Chem. Res., 30(3), 585-589 (1991). 


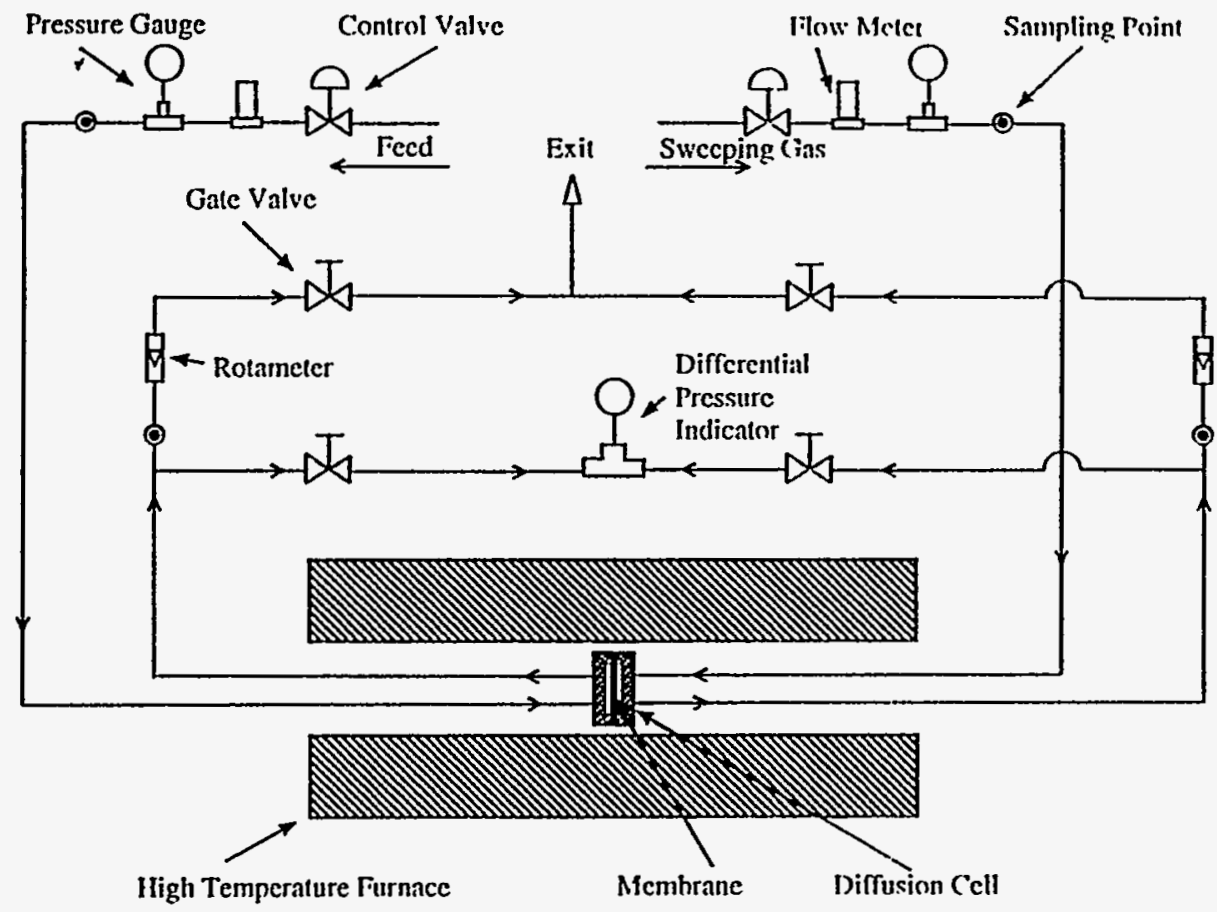

Figure 1. Schematic of Permeability Measurement Setup

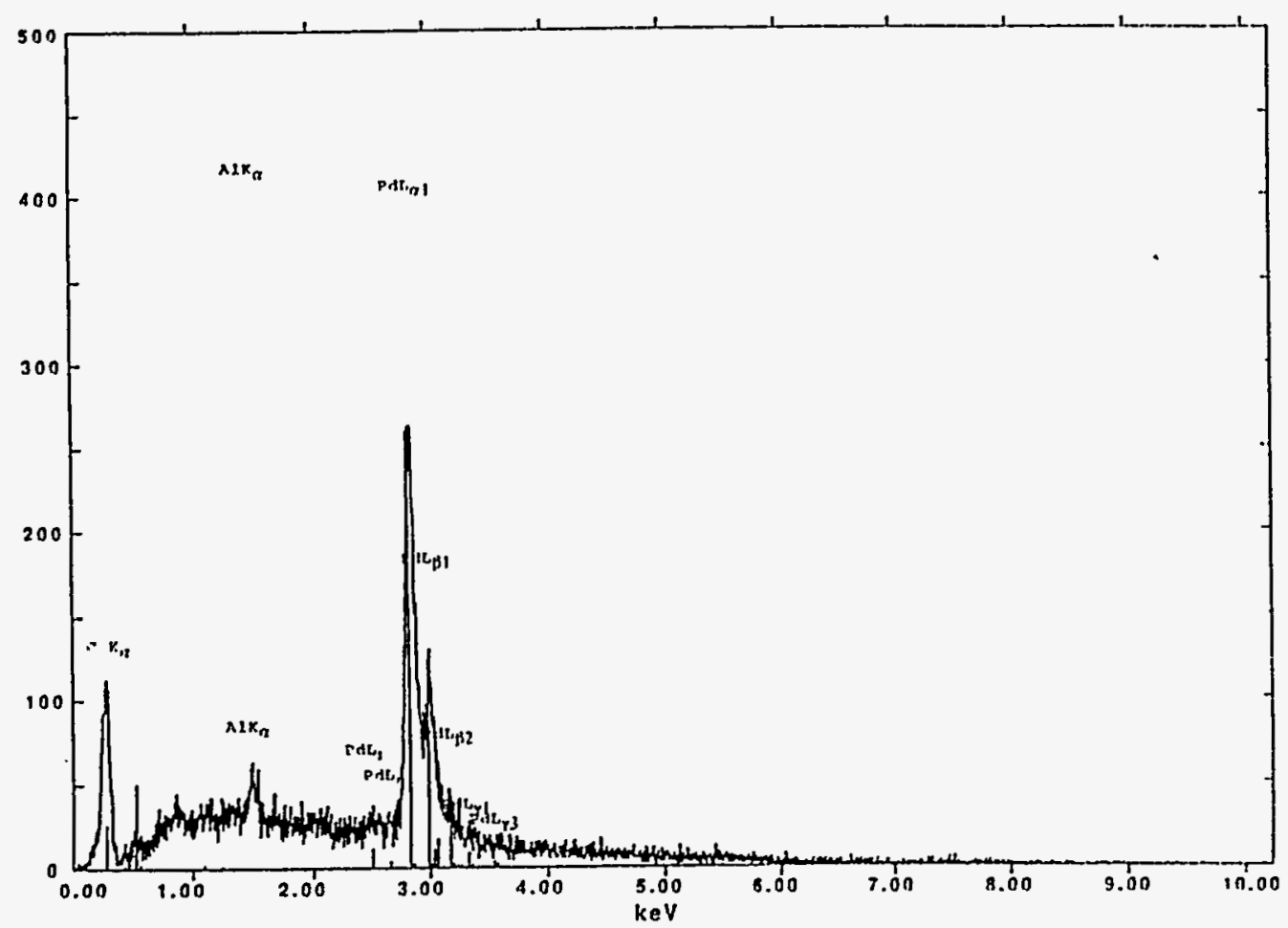

Figure 2. EDX Analysis of Electroless Deposited Palladium Film on Ceramic Substrate 


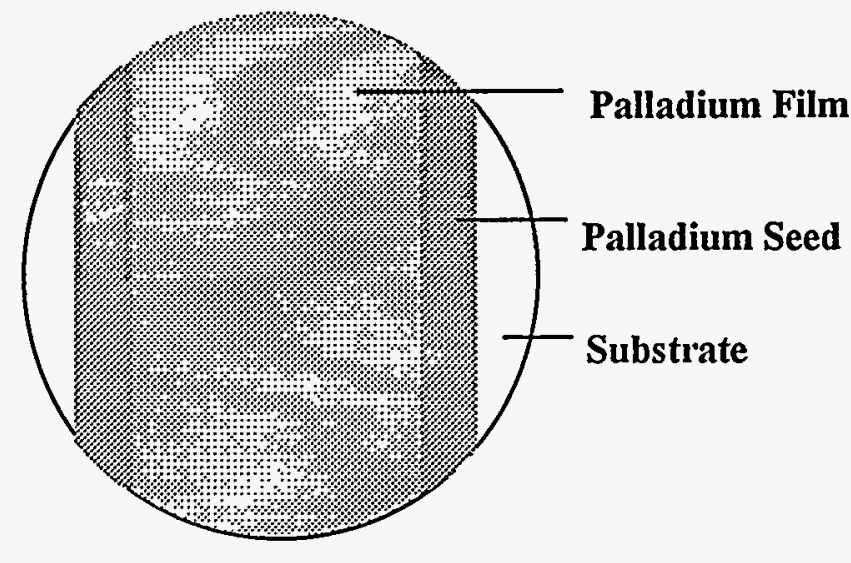

(a)

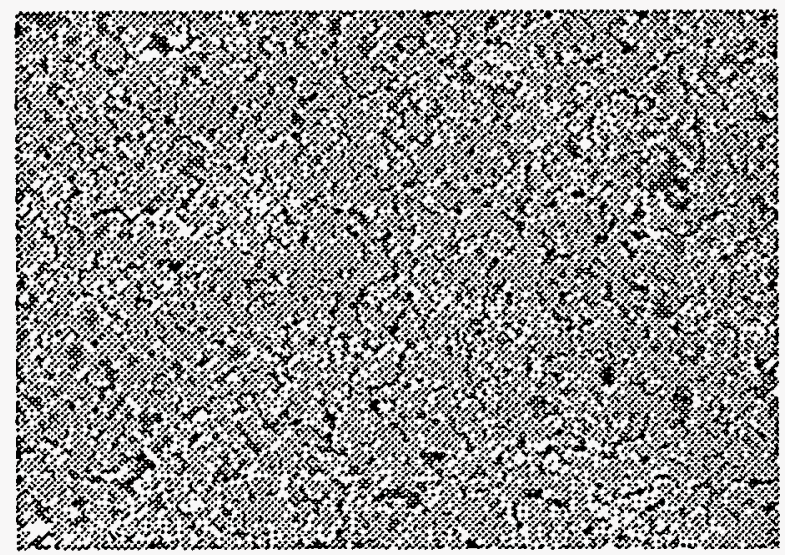

(c)

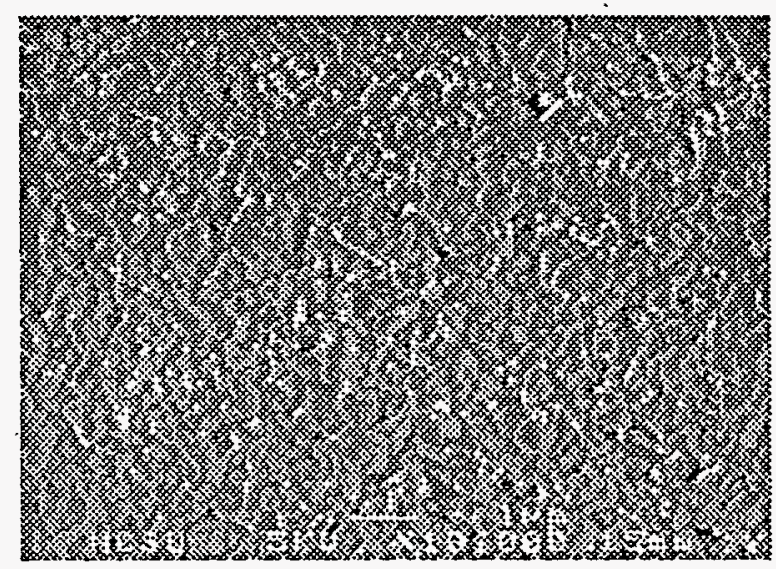

(b)

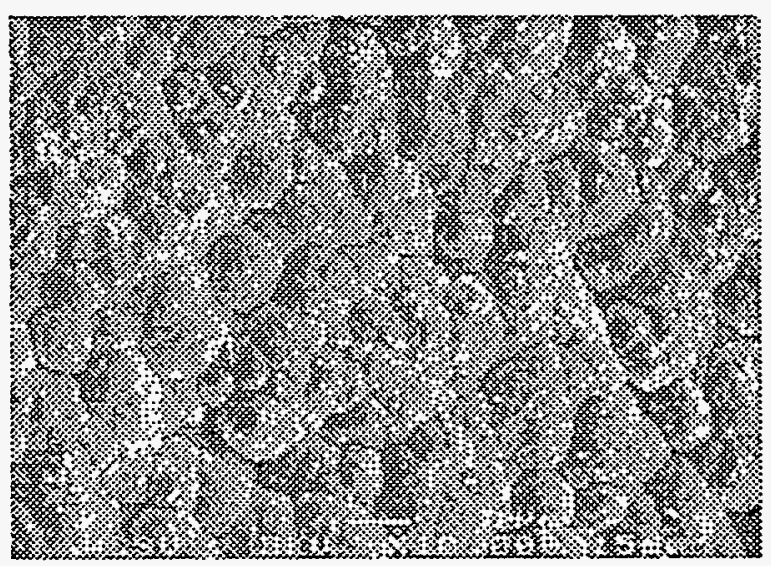

(d)

Figure 3. SEM Micrographs of Palladium-Ceramic Composite Membrane: (a) Sample Specimen, (b) SEM of Substrate, (c) SEM of Sensitized and Activated Substrate Surface, and (d) SEM of Electroless Deposited Palladium Film on Ceramic Substrate 


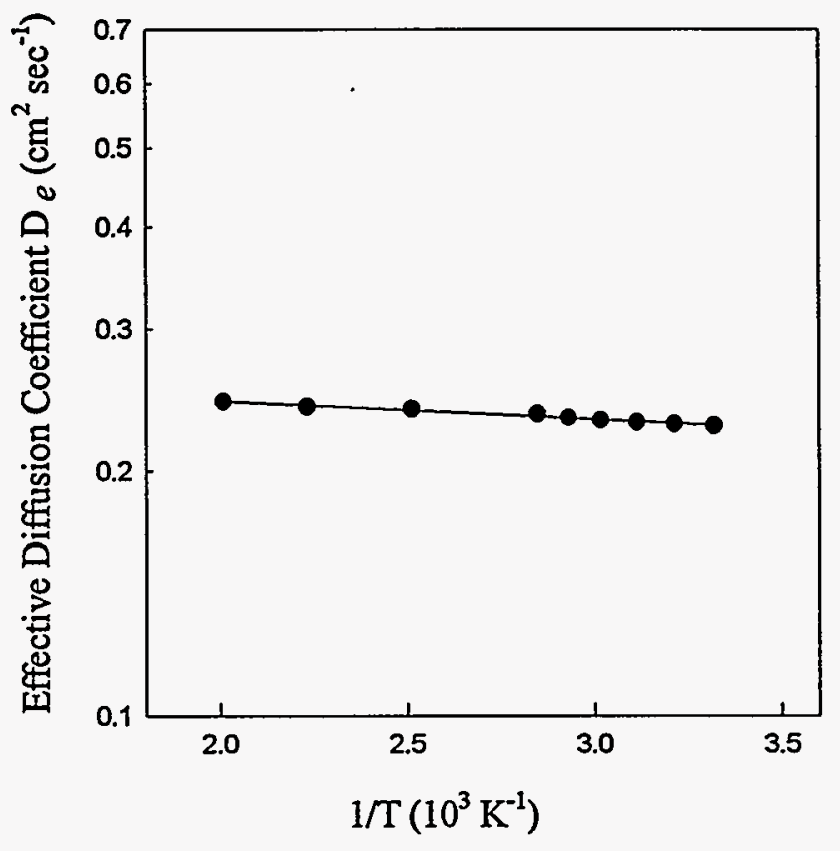

Figure 4. Correlation of Effective Diffusivity of Hydrogen with Temperature for the Ceramic Substrate

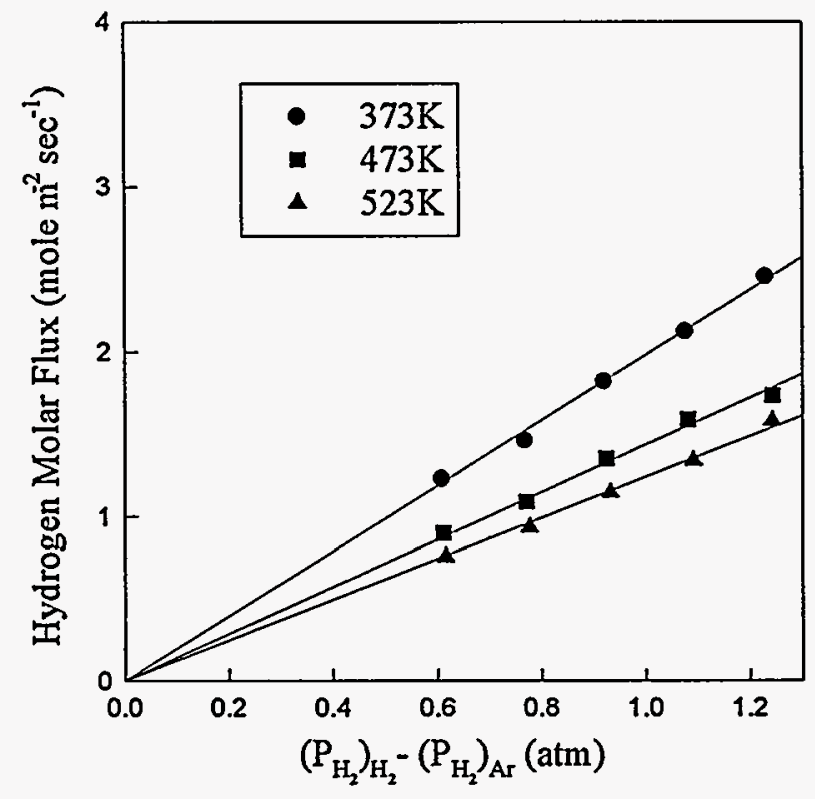

Figure 5. Effect of Transmembrane Hydrogen Partial Pressure Difference on Fluxes at various Temperatures Through Ceramic Substrate 


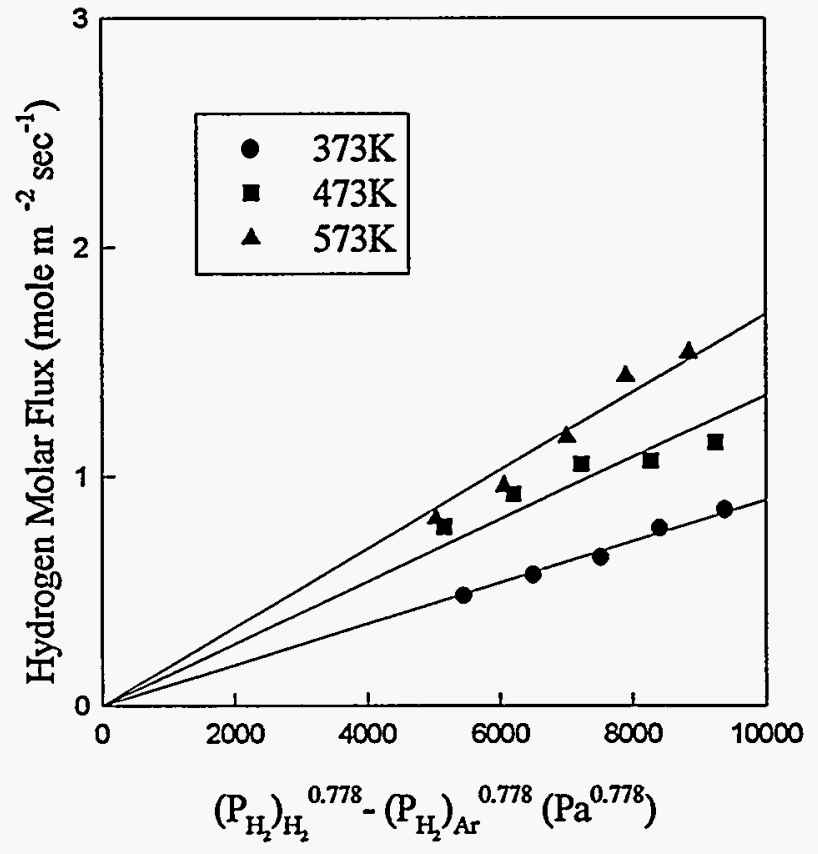

Figure 6. Effect of Driving Force $\left(\left(\mathrm{P}_{\mathrm{Hz}}\right)_{\mathrm{H} 2}{ }^{\mathrm{n}}-\left(\mathrm{P}_{\mathrm{H} 2}\right)_{\mathrm{Ar}}{ }^{\mathrm{n}}\right)$ on Fluxes at various Temperatures Through Palladium-Ceramic Composite Membrane with Film Thickness of $8.5 \mu \mathrm{m}(\mathrm{n}=0.778)$

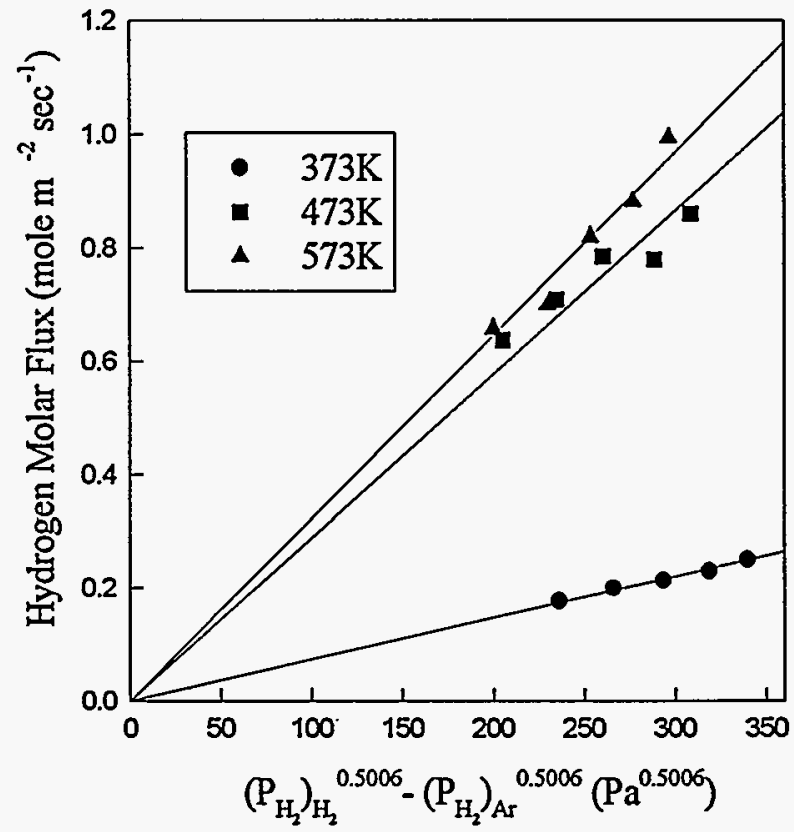

Figure 7. Effect of Driving Force $\left(\left(\mathrm{P}_{\mathrm{H} 2}\right)_{\mathrm{H} 2}{ }^{\mathrm{n}}-\left(\mathrm{P}_{\mathrm{H} 2}\right)_{\mathrm{Ar}}{ }^{\mathrm{n}}\right)$ on Fluxes at various Temperatures Through Palladium-Ceramic Composite Membrane with Film Thickness of $12 \mu \mathrm{m}(\mathrm{n}=0.5006)$ 